\title{
O PNAIC E SUA INFLUÊNCIA NA FORMAÇÃO DE PROFESSORES ALFABETIZADORES NO MUNICÍPIO DE PROPRIÁ/SE
}

\author{
PNAIC AND ITS INFLUENCE IN THE TRAINING OF LITERACY TEACHERS IN THE MUNICIPALITY OF \\ PROPRIÁ
}

\author{
Maria Dilma Santos Timóteo¹, William Timóteo², Kaio Eduardo de Jesus Oliveira ${ }^{3}$
}

\section{RESUMO}

O presente artigo tem como objeto o Pacto Nacional pela Alfabetização na Idade Certa (PNAIC) na formação continuada dos seus alfabetizadores, trazendo resultados de uma pesquisa realizada junto a estes profissionais, bem como a exploração da leitura e escrita dos estudantes do $1^{\circ}$ ao $3^{\circ}$ ano e das Salas Multisseriadas do Ensino Fundamental da Rede Municipal de Ensino de Propriá/SE, tendo como principal objetivo analisar a influência do PNAIC na formação de professores do município de Propriá/SE, bem como a importância da integração do processo de alfabetização e letramento para a educação básica. Sendo assim, tem abordagem quanti-qualitativa efetuada por um estudo de caso, com método de coleta de dados. Busca a socialização de experiências, favorecendo a articulação entre teoria e prática no contexto escolar. Dessa forma, verificou-se que o Pacto foi de suma importância para os professores, uma vez que proporcionou uma reflexão mais crítica sobre suas próprias práticas. Contudo, vislumbra-se que a formação em Propriá/SE foi de grande relevância e, por isso, há a necessidade de aprofundamento de estudos sobre a organização do trabalho pedagógico por meio de projetos, sequências didáticas e jogos. Conclui-se que o processo de formação contribui para a ampliação e aprofundamento, cada vez mais, de estudos teóricos sobre alfabetização e letramento, articulando-os aos estudos acerca de outras disciplinas, de modo a cooperar para avanços nos aspectos relacionados ao ensino-aprendizagem.

PALAVRAS-CHAVE: Formação Continuada. Alfabetização. Letramento.

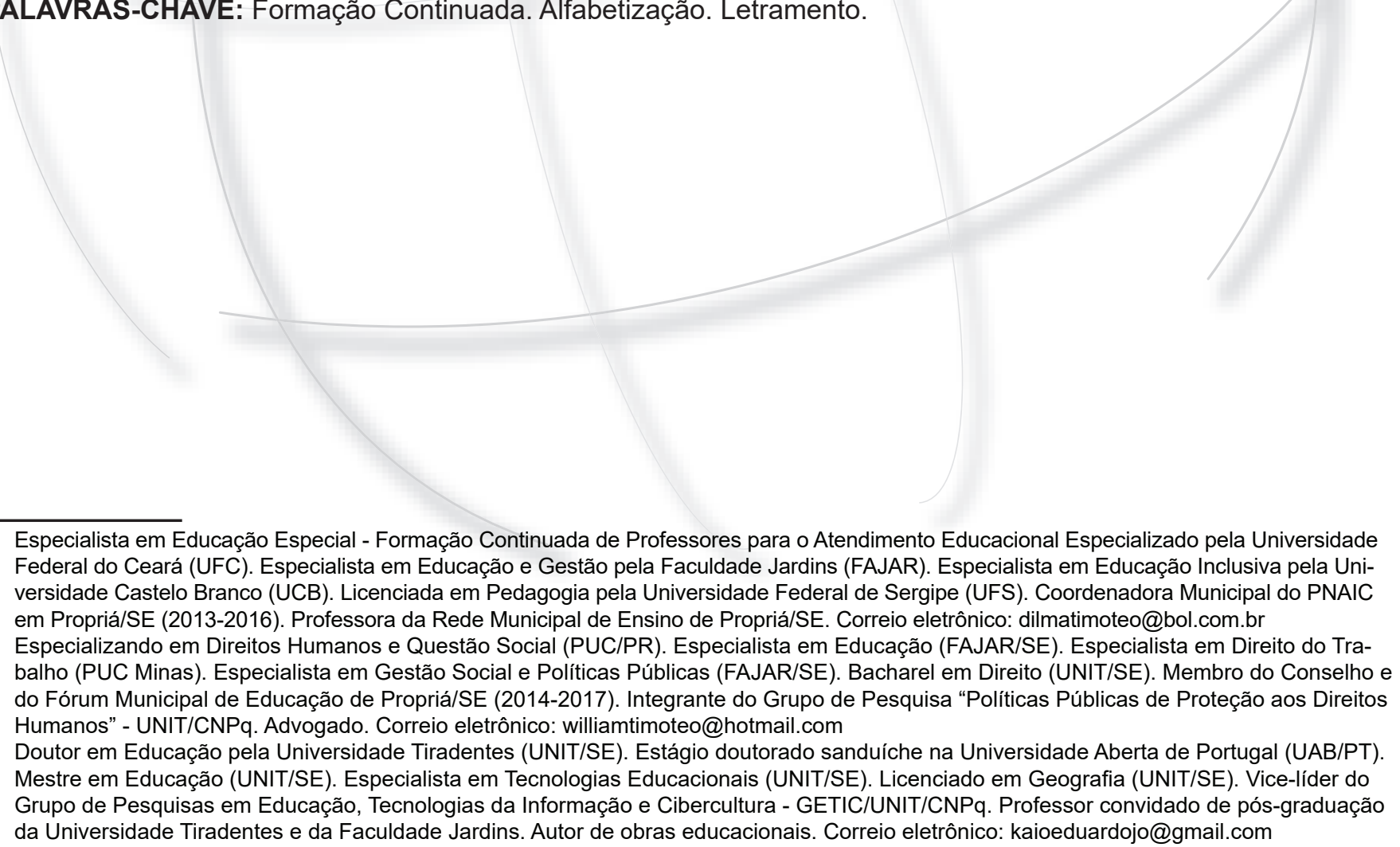

1 Especialista em Educação Especial - Formação Continuada de Professores para o Atendimento Educacional Especializado pela Universidade Federal do Ceará (UFC). Especialista em Educação e Gestão pela Faculdade Jardins (FAJAR). Especialista em Educação Inclusiva pela Universidade Castelo Branco (UCB). Licenciada em Pedagogia pela Universidade Federal de Sergipe (UFS). Coordenadora Municipal do PNAIC em Propriá/SE (2013-2016). Professora da Rede Municipal de Ensino de Propriá/SE. Correio eletrônico: dilmatimoteo@bol.com.br

2 Especializando em Direitos Humanos e Questão Social (PUC/PR). Especialista em Educação (FAJAR/SE). Especialista em Direito do Trabalho (PUC Minas). Especialista em Gestão Social e Políticas Públicas (FAJAR/SE). Bacharel em Direito (UNIT/SE). Membro do Conselho e do Fórum Municipal de Educação de Propriá/SE (2014-2017). Integrante do Grupo de Pesquisa "Políticas Públicas de Proteção aos Direitos Humanos" - UNIT/CNPq. Advogado. Correio eletrônico: williamtimoteo@hotmail.com

3 Doutor em Educação pela Universidade Tiradentes (UNIT/SE). Estágio doutorado sanduíche na Universidade Aberta de Portugal (UAB/PT). Grupo de Pesquisas em Educação, Tecnologias da Informação e Cibercultura - GETIC/UNIT/CNPq. Professor convidado de pós-graduação da Universidade Tiradentes e da Faculdade Jardins. Autor de obras educacionais. Correio eletrônico: kaioeduardojo@gmail.com 


\begin{abstract}
This article has as its object the National Pact for Literacy at the Right Age (PNAIC) in the continuing education of its literacy teachers, bringing results of a research carried out with these professionals, as well as the exploration of reading and writing by students from the 1st to the 3rd year and Multiseriate Rooms of Elementary Education of the Municipal Education Network of Propriá / SE, with the main objective of analyzing the influence of PNAIC in the training of teachers in the municipality of Propriá-SE, as well as the importance of integrating the process of literacy and literacy for basic education. Therefore, it has a quantitative and qualitative approach carried out by a case study, using a data collection method. It seeks the socialization of experiences, favoring the articulation between theory and practice in the school context. Thus, it was found that the Pact was of paramount importance for teachers, since it provided a more critical reflection on their own practices. However, it appears that the training in Propriá / SE was of great relevance and, therefore, there is a need for further studies on the organization of pedagogical work through projects, didactic sequences and games. It is concluded that the training process contributes to the widening and deepening, more and more, of theoretical studies on literacy and literacy, articulating them to studies on other subjects, in order to cooperate for advances in aspects related to teaching-learning .
\end{abstract}

KEYWORDS: Continuing Education. Literacy. Literature.

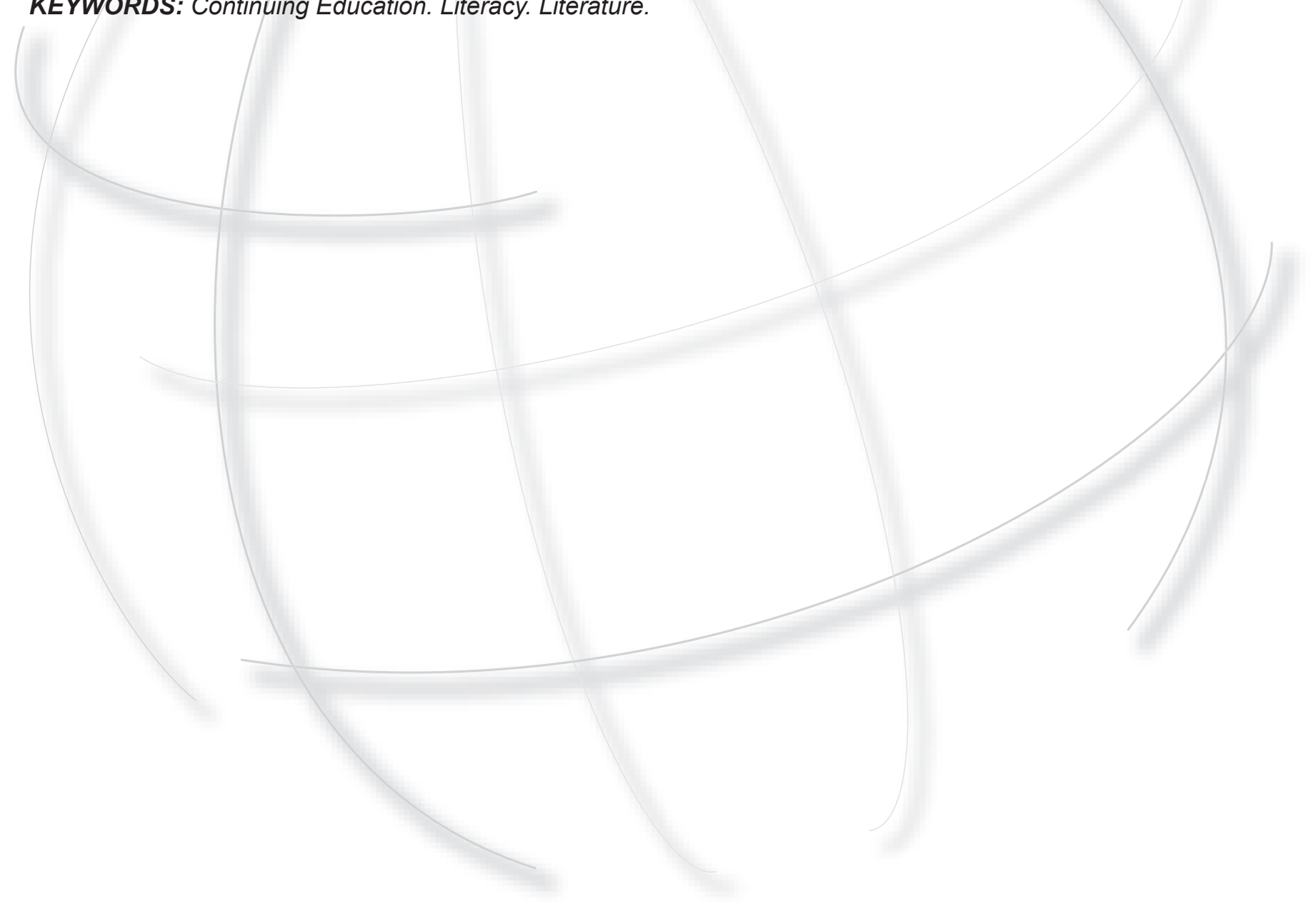




\section{INTRODUÇÃO}

O intuito desta pesquisa é analisar a influência do Pacto Nacional pela Alfabetização na Idade Certa (PNAIC) na formação de professores do município de Propriá/SE. O PNAIC é um programa de formação continuada para professores alfabetizadores, tem como proposta auxiliar na formação de professores e na melhoria da qualidade do processo de ensino e aprendizagem no ciclo de alfabetização.

Nesse sentido, o Programa Nacional pela Alfabetização na Idade Certa tornou-se uma das principais políticas públicas educacionais implementadas no $\mathrm{Mu}$ nicípio de Propriá, voltadas especialmente ao aperfeiçoamento das estratégias didáticas dos profissionais da educação. Além disso, oferece uma metodologia de formação baseada na relação entre ensino, estudo e pesquisa, com o objetivo de explorar os conhecimentos prévios dos professores alfabetizadores, proporcionando um compartilhamento de saberes e estratégias metodológicas que os levam à transformação de sua prática docente.

Dentre outros objetivos, a formação continuada propõe novas metodologias e coloca os profissionais a par das discussões teóricas atuais, com a intenção de contribuir para as mudanças que se fazem necessárias à melhoria da ação pedagógica na escola. É certo que conhecer novas teorias integra o processo de construção profissional, mas não é o suficiente, se não possibilitam ao professor relacioná-las ao seu conhecimento prático construído no seu cotidiano (NÓVOA, 1995; PERRENOUD, 2000).

Nessa perspectiva, entende-se que uma formação continuada consistente, com foco na reflexão-prática e aliada à disponibilização de materiais didáticos, é de suma importância para a concretização de uma alfabetização de qualidade para todas as crianças, uma vez que culmina em um processo que transforma a pessoa de um ser biológico para um ser social.

Nesse contexto, não basta que a alfabetização seja na perspectiva de apropriar-se do sistema de escrita alfabético, sendo necessário também adquirir as habilidades que possibilitem a leitura e escrita de forma adequada, com domínio pleno do referido sistema. Para tanto, torna-se indispensável que o professor compreenda, inicialmente, a importância e o significado de alfabetização e letramento, e assim alfabetizar em contex- tos de letramento, o que tem sido trabalhado de forma constante nas formações. Nesse sentido, percebe-se a necessidade de realizar a formação continuada do PNAIC não só para os professores alfabetizadores, mas também para todos os docentes da educação básica.

A partir dessas considerações, a fim de obter informações pautadas nas observações de cada profissional, para a realização desta pesquisa foi aplicado um questionário para coleta e levantamento de dados a partir de algumas questões como: 1) Foram desenvolvidas ações baseadas nas orientações do PNAIC durante o ano de 2018? Se sim, quais foram os recursos utilizados e como foram desempenhadas as atividades em sua escola? 2) Como você compreende as ações do PNAIC? Aponte os pontos que poderiam ser destacados sobre esse Programa. 3) Em sua escola, são promovidas ações ou meios para a recuperação dos alunos de menor rendimento? Explique sobre essas ações.

Diante de todo o delineado, traçar-se-á a importância do pacto e a sua contribuição para as práticas docentes e pedagógicas, observando o desenvolvimento de ações acerca dos direitos de aprendizagem das crianças para os processos de avaliação e acompanhamento da aprendizagem, para o planejamento e avaliação das situações didáticas e para o conhecimento e uso dos materiais distribuídos pelo Ministério da Educação, voltados para a melhoria da qualidade do ensino no ciclo de alfabetização.

Assim, o estudo de caso com abordagem qualitativa nesta pesquisa, compreender como a formação continuada de professores a partir do PNAIC pode contribuir para o desenvolvimento de práticas pedagógicas na Rede Municipal de Ensino de Propriá/SE, bem como a importância da integração do processo de alfabetização e letramento na composição dessas práticas. A coleta de dados realizou-se também através da aplicação das sondagens ${ }^{4}$ de leitura e escrita com estudantes do $1^{\circ}$ ao $3^{\circ}$ ano e Salas Multisseriadas do Ensino Fundamental, além das entrevistas com as professoras sobre as ações desenvolvidas durante o ano 2018, por meio das atividades desenvolvidas nas turmas do ciclo de alfabetização.

Sendo assim, na segunda seção deste texto apresentamos alguns aspectos sobre a formação continuada de professores e sua relevância para a efetivação de es-

4 Atividade de diagnóstico utilizada para checar os conhecimentos prévios dos estudantes, e ainda, para avaliar a evolução do processo de aprendizagem. A partir dela, definir-se-á o trabalho que necessita ser desenvolvido pelo professor. 
tratégias didáticas e práticas pedagógicas, em seguida destacaremos a relevância do PNAIC para o município de Propriá, em Sergipe e os aspectos gerais do estudo de caso e os resultados da pesquisa.

\section{ALGUNS ASPECTOS DA FORMAÇÃO CONTINUA- DA NO ÂMBITO DO PNAIC}

No contexto das reformas educacionais e nas discussões relativas às políticas públicas brasileiras, muito se tem escrito e discutido sobre a formação continuada. Por isso, optou-se pelo estudo sobre políticas de formação continuada para professores na cidade de Propriál SE, tendo como objeto o Pacto Nacional pela Alfabetização na Idade Certa.

O PNAIC é um compromisso assumido, em regime de colaboração entre todos os Entes Federados, incluindo a participação das famílias e da comunidade, a fim de implementar o Plano de Metas Compromisso Todos pela Educação, instituído pelo Decreto $\mathrm{n}^{\circ} 6.094$, de 24 de abril de 2007, e tem dentre as suas diretrizes a de alfabetizar as crianças até, no máximo, os 08 (oito) anos de idade, aferindo os resultados por exame periódico específico (BRASIL, 2007).

Nessa conjuntura, constitui-se um programa do Ministério da Educação, que se desenvolve em parceria com universidades públicas brasileiras e secretarias de educação, do qual se extrai que não há como garantir a efetividade da formação docente sem a participação ativa de todos os entes governamentais, uma vez que possuem funções específicas a fim de garantir o seu bom andamento. Contudo, a formação de docentes é uma tarefa complexa, que precisa contar com o esforço conjunto de diferentes segmentos da sociedade.

Sendo assim, no PNAIC, quatro princípios centrais são considerados ao longo do desenvolvimento do trabalho pedagógico:

1. O Sistema de Escrita Alfabética é complexo e exige um ensino sistemático e problematizador;

2. O desenvolvimento das capacidades de leitura e de produção de textos ocorre durante todo o processo de escolarização, mas deve ser iniciado logo no início da Educação Básica, garantindo acesso precoce a gêneros discursivos de circulação social e a situações de interação em que as crianças se reconheçam como protagonistas de suas próprias histórias;
3. Conhecimentos oriundos das diferentes áreas podem e devem ser apropriados pelas crianças, de modo que elas possam ouvir, falar, ler, escrever sobre temas diversos e agir na sociedade;

4. A ludicidade e o cuidado com as crianças são condições básicas nos processos de ensino e de aprendizagem.

Nessa concepção, a formação continuada do PNAIC para alfabetização é, sem dúvida, uma das prioridades nacionais no contexto atual, pois o professor alfabetizador tem a função de auxiliar na formação para o bom exercício da cidadania, uma vez que cada um deve estar consciente de que a sua formação deve ser contínua e está relacionada ao seu dia a dia.

Para Nóvoa (2003, p. 23), "o aprender contínuo é essencial e se concentra em dois pilares: a própria pessoa, como agente, e a escola como lugar de crescimento profissional permanente". O autor defende ainda que a formação continuada se dá de maneira coletiva, por troca de experiências e reflexões como instrumentos de análises.

Por sua vez, Silva (2007, p. 100) complementa que a formação continuada carrega em sua essência a necessidade de estimular os professores a se apropriarem do saber fazer, de modo a construir autonomia e concretizar uma "[...] prática crítico-reflexiva, abrangendo a vida cotidiana da escola e o saber derivado da experiência docente", fazendo com que a própria prática pedagógica torne-se objeto de estudo, reflexão e pesquisa.

Confirmando essa ideia, Freire (2002, p. 43-44) ressalta que a prática da pesquisa é inerente ao trabalho do professor. Na sua compreensão:

[...] o que há de pesquisador no professor não é uma qualidade ou uma forma de ser ou de atuar que se acrescente à de ensinar. Faz parte da natureza da prática docente a indagação, a busca, a pesquisa. $\mathrm{O}$ de que se precisa é que, em sua formação permanente, o professor se perceba e se assuma, porque professor, como pesquisador.

Ao assumir o processo contínuo de indagação, de busca, de pesquisa e ensino, o professor agrega ao seu currículo um ponto positivo, pois consegue aliar prática $\mathrm{e}$ teoria, inovando em sua aula, trazendo novas experiências e ensinando aos seus estudantes através de vários 
métodos de aprendizagem. Tal processo deve ser instigado sempre para ser base propulsora de um ensino de qualidade. Nessa perspectiva, Fazenda (2008, p. 10) sustenta que:

Aprender a pesquisar, fazendo pesquisa, é próprio de uma educação interdisciplinar, que, segundo nossos dados, deveria se iniciar desde a pré-escola. Uma das possibilidades de execução de um projeto interdisciplinar na universidade é a pesquisa coletiva, em que exista uma pesquisa nuclear que catalise as preocupações dos diferentes pesquisadores, e pesquisas-satélites em que cada um possa ter o seu pensar individual e solitário. $\mathrm{Na}$ pesquisa interdisciplinar, está a possibilidade de que cada pesquisador possa revelar a sua própria potencialidade, a sua própria competência.

Dessa forma, verifica-se que a pesquisa no processo educacional está interligada ao aprendizado e reflexões sobre as práticas do dia a dia, fazendo a ponte entre os saberes populares e científicos, e entre o que os estudantes estudam e como relacionam os saberes acadêmicos ao âmbito familiar e grupos sociais.

Partindo do pressuposto de que todos são sujeitos históricos e vivem em constantes mudanças, a formação do PNAIC ofertada aos professores torna-se indispensável, pois é um momento de aprender novos conceitos, participar de discussões atuais referentes à educação e, principalmente, refletir sobre a sua ação docente. Nesse prima, Perrenoud (2000, p. 139) destaca que:

É preciso reconhecer que os professores não possuem apenas saberes, mas também competências profissionais que não se reduzem ao domínio dos conteúdos a serem ensinados, e aceitar a ideia de que a evolução exige que todos os professores possuam competências antes reservadas aos inovadores ou àqueles que precisavam lidar com públicos difíceis.

Isso quer dizer que a formação continuada reforça, ainda mais, a ideia de que a educação é um processo em constante desenvolvimento, no qual o professor atualiza-se, construindo na sua prática, a reflexão crítica sobre as suas ações pedagógicas, numa permanente construção e reconstrução da identidade docente, participando ativamente do mundo que o cerca.

Para ilustrar esse novo referencial, destacam-se os depoimentos das professoras alfabetizadoras sobre a validade do PNAIC em relação ao processo de ensino e aprendizagem:

Vejo que o Programa é muito significativo, uma maravilha, [...] através do Programa a interação entre o conhecimento teórico e prático, fazendo com que as escolas se tornassem locais onde a alfabetização se constituísse de algo prazeroso, com atividades como Leitura Deleite, contação de histórias, jogos de alfabetização e reflexão através do Livro da Vida, trazendo interação, divertimento e aprendizagens, procedimentos para organização e sistematização do trabalho pedagógico: rotina, projetos, sequência didática... Com isso, nós alfabetizadores pudemos inovar, reinventar e compartilhar nossas práticas de alfabetização, analisando a escola que temos e a escola que queremos. Porém na escola ficávamos sozinhas, não encontrávamos espaços nem colaboração dos gestores da escola para que às possibilidades de melhoria na aprendizagem realmente fosse concretizada significativamente como o Programa requer, isto é, precisamos de uma transformação na gestão da escola para que o PNAIC de fato aconteça. (N. S. B.) ${ }^{5}$.

Para mim é um programa positivo, pois melhorou bastante a minha prática pedagógica e veio para somar e enriquecer os meus conhecimentos e as minhas expectativas foram atendidas com êxito. (S.R.V.).

Compreendo que esse Programa é de grande validade, é maravilhoso, pois aprendi nas formações continuadas de como trabalhar com meus alunos, como: Direitos de aprendizagem com jogos e brincadeiras para o desenvolvimento da consciência fonológica; procedimentos para organização e sistematização do trabalho pedagógico: rotina, projetos, sequência didática; o trabalho adequado com gênero textual, sempre tomando como referência a realidade dos meus alunos e também avaliação como processo de diagnóstico. Além do mais, todas as discussões e propostas promovi-

5 A sigla entre parênteses refere-se às iniciais do nome da amostra pesquisada. 
das nos encontros sempre envolviam questões relativas ao conteúdo que seria trabalhado em sala de aula, referencial ao conhecimento do aluno. (M. H. S. B. P.).

As ações do PNAIC vêm contribuindo de forma grandiosa, orientando o professor em sala de aula, com conhecimentos indispensáveis a aprendizagem do aluno, mostrando formas e métodos para alcançar melhoria na formação educacional do professor e aluno. (E. V. S.).

É um programa que nos faz crescer profissionalmente e pessoalmente através da formação continuada, a troca de experiências com os colegas, a harmonia nos encontros, os objetivos alcançados com os nossos alunos, os recursos fornecidos, tudo isso, fazendo com que tenhamos a consciência do nível de competências em que nos encontramos, tanto nós como os alunos, fazendo ainda com que realizemos uma autoavaliação, melhorando a prática pedagógica de cada um de nós em sala de aula. (M. H. S.) Ações positivas voltadas para situações concretas significativas a realidade do aluno proporcionando com satisfação de forma prazerosa e lúdica. (E. M. S.).

Estimula o desenvolvimento da criatividade na prática cotidiana em sala de aula expandindo a aprendizagem, contribuindo para o crescimento do professor e do alunado. (M. D. C. S.)

Percebe-se nos depoimentos a satisfação em participar do pacto, uma vez que ele traz a atuação profissional para o eixo das práticas formativas, pois sua exigência metodológica é a consideração efetiva dos processos de aprendizagem dos professores alfabetizadores, compreendendo como se apropriam e constroem conhecimento e entendendo que a aprendizagem mobiliza, ao mesmo tempo, suas características pessoais, bem como suas experiências de vida e profissional.

Dessa forma, Nóvoa (1997, p. 26) destaca que "a troca de experiências e a partilha de saberes consolidam espaços de formação mútua, nos quais cada professor é chamado a desempenhar, simultaneamente, o papel de formador e de formando". Nesse sentido, deve-se observar a flexibilização das ações formativas, considerando as necessidades de aprendizagem dos professores e os conhecimentos prévios já trazidos pelos estudantes.
Notam-se também nos depoimentos os principais desafios encontrados por algumas educadoras, as quais não possuíam em sua escola a base e o apoio necessário para desenvolver as ações propostas pelo programa de formação.

A falta de envolvimento da equipe gestora nas ações do PNAIC e a infraestrutura precária das unidades escolares dificultava a obtenção de resultados mais eficazes. Contudo, movidas pelo sentimento de mudança e norteadas pelas orientações adquiridas nas formações, as professoras conseguiram ultrapassar a barreira administrativa e obtiveram resultados significativos.

Algumas dificuldades são sempre vivenciadas em todo o processo de aprendizagem. Entretanto, percebe-se que a formação continuada proporcionada pelo pacto foi de suma importância para as alfabetizadoras, pois se tornou o campo de atualização sobre os métodos de alfabetização e reflexão sobre os trabalhos em sala de aula, culminando em uma prática que articula alfabetização e letramento, entendendo a leitura e a escrita como função social.

Fica impossível para o professor mudar as suas práticas e seu saber fazer pedagógico se não tiver a oportunidade de participar de cursos, a fim de vivenciar novas experiências, novas pesquisas, novas formas de ver e pensar, tentando abranger as possíveis dificuldades de uma determinada situação com finalidades claras e definidas, e procurando adquirir habilidades e competências necessárias ao desenvolvimento.

\section{METODOLOGIA}

A necessidade em realizar a pesquisa sobre a influência do PNAIC nas práticas pedagógicas e docentes dos professores alfabetizadores da Rede Municipal de Ensino de Propriá/SE, atrelada à impossibilidade de entrevistar cada um desses professores que participaram da formação continuada do programa, fez com que fossem selecionados 07 (sete) profissionais, lotados em unidades da zona rural e urbana.

A coleta de dados realizou-se através da aplicação das sondagens de leitura e escrita com estudantes do $1^{\circ}$ ao $3^{\circ}$ ano e Salas Multisseriadas ${ }^{6}$ do Ensino Fundamental, além de entrevistas com as professoras titu-

6 Forma de organização do ensino que reúne, simultaneamente, alunos de várias séries com idades e níveis de conhecimento diferentes, em uma única sala de aula. 
lares das salas de aula sobre as ações desenvolvidas durante a vigência do pacto por meio das atividades realizadas nas turmas do ciclo de alfabetização.

As questões elaboradas caracterizaram-se pela abordagem quanti-qualitativa, e o material colhido no decorrer da pesquisa buscou analisar e refletir sobre as ações realizadas nas turmas investigadas, a fim de obter reflexos da influência do PNAIC na prática docente, bem como no desenvolvimento dos alunos.

Percebe-se, através das respostas, que no processo de apropriação de novos conhecimentos, foram incorporadas inúmeras atividades escolares em Língua Portuguesa e Matemática, envolvendo as demais disciplinas de acordo com as necessidades do estudante e dos propósitos educativos, das quais podemos citar: cantinho de leitura e matemática, continuidade ao projeto "um convite à leitura com contação de história"; sondagens bimestrais de leitura e escrita; concurso e gincana estudantil; produção textual; feira de cultura; campeonatos de jogos matemáticos; excursões para estudo; simulação de mercadinhos; trabalho com simetria; formas geométricas e cartografia, dentre outros.

Houve a confirmação que durante $o$ ano letivo foi desenvolvida a proposta do programa, partindo da ressignificação do mundo para o estudante e professor na articulação de ação-reflexão-ação, mostrando a possibilidade de as escolas transformarem as salas de aula em uma oficina de leitores e escritores, auxiliando-os na alfabetização matemática dentro da perspectiva de letramento, pautada pela inclusão e respeito à diversidade.

As professoras alfabetizadoras nas suas respostas demonstraram as suas evoluções e ampliações do seu campo de trabalho profissional, pois identificamos em suas falas as competências que foram desenvolvidas nas formações continuadas, corroborando com Perrenoud (2000), ao asseverar que a formação profissional contínua se organiza em determinadas áreas prioritárias, dentre as quais estão as competências básicas que cabem ao educador.

Cabe-nos, nesse momento, descrever que foi percebida, cada vez mais, a importância do Pacto Nacional pela Alfabetização na Idade Certa porque possui um conjunto integrado de ações, materiais e referências curriculares e pedagógicas, como objetivo de analisar e discutir fatos e situações do ponto de vista da alfabetização e letramento, reconhecendo a necessidade e as oportunidades de atuar de modo reativo e propositivo para a garantia da melhoria do processo de ensino e aprendizagem.

\section{PNAIC EM PROPRIÁ: DESAFIOS E PERSPECTIVAS}

Cumpre-nos realizar algumas observações quanto aos resultados relativos às entrevistas sobre a influência do PNAIC na formação continuada e sondagens de leitura e escrita, além daquilo que foi incorporado pelos professores em suas práticas no cotidiano escolar, evidenciando claramente a importância que ganhou os temas pedagógicos estudados, tais como: direitos de aprendizagem; jogos e brincadeiras para o desenvolvimento da consciência fonológica; procedimentos para organização e sistematização do trabalho pedagógico; o trabalho adequado com gênero textual, números e operações etc.

Compete registrar que as mencionadas atividades sempre tomam como referência a realidade do aluno, a fim de possibilitar-lhe a atribuição de maior sentido ao conteúdo estudado, realizando ainda uma avaliação como processo de diagnóstico e norteadora do planejamento estratégico.

Vislumbra-se, nesse sentido, que todos juntos aprenderam a mediar os estudos, respeitando as vivências uns dos outros e sendo sensíveis ao tempo que precisavam para se apropriarem dos conhecimentos estudados na formação.

Ainda, construíram-se estratégias para/idar com o cansaço na hora da formação, confeccionaram jogos dinâmicos e atividades a serem desenvolvidos em salas de aula, fazendo com que fossem utilizadas caixas lacradas de jogos do armário das escolas, proporcionando também momentos de planejamento e reflexão sobre os conhecimentos construídos na formação, juntamente com as experiências vivenciadas.

Faz-se necessário trazer o rompimento das práticas tradicionais de alfabetização, em função de um trabalho pautado na reflexão sobre as teorias e as propostas didáticas do "alfabetizar letrando", sendo descoberto o valor das atividades diversificadas na rotina, nos projetos e nas sequências didáticas, havendo assim a teorização da sua prática, de forma a relatar com propriedade suas vivências como mediador do conhecimento.

Convencidas de que as situações desafiadas são fontes úteis de aprendizagem e um processo abrangen- 
te, incluímos o estudante, o professor, o programa, os materiais, a organização da sala de aula, o clima da aula e da instituição escolar como aspectos significativos que interferem no processo de ensino aprendizagem.

\section{CONCLUSÃO}

Diante do exposto, verifica-se que a educação exige paciência, esforço e dedicação. Requer reflexão-ação-reflexão em todas as suas dimensões. A implantação de procedimentos metodológicos diversificados pelos educadores é a peça chave para um ensino de qualidade, focando o olhar na aprendizagem dos alunos e inovando sua metodologia na aplicabilidade dos conteúdos em sala de aula.

Nota-se que os temas abordados na formação continuada do PNAIC deram aos professores alfabetizadores uma amplitude de conhecimentos, estabelecendo associações e significações que enriquecem as suas possibilidades de aprendizagem.

Diante disso, verifica-se que os professores realmente levaram a sério todas as competências adquiridas, e a partir dessa vivência foi perceptível a importância da formação continuada para o processo de alfabetização, reconhecendo em uma determinada disciplina os conteúdos a ensinar e a sua tradução em objetivos de aprendizagem, trabalhando a partir das representações dos alunos, dos erros e obstáculos à aprendizagem.

Os professores passaram também a gerir a progressão das aprendizagens, concebendo situações-problema ajustadas aos níveis e possibilidades dos alunos, objetivando assim adquirir uma visão longitudinal dos objetivos do ensino, estabelecendo laços com teorias subjacentes às atividades de aprendizagem, observando e avaliando os alunos em situações de aprendizagem, segundo uma abordagem formativa, estabelecendo balanços periódicos de competências e tomando decisões progressivas.

O PNAIC despertou ainda o gerenciamento da heterogeneidade dentro da uma sala de aula, ampliando a gestão da aula para um espaço mais vasto, praticando o apoio integrado, trabalhando com alunos em grande dificuldade, desenvolvendo a cooperação entre alunos e certas formas simples de ensino mútuo.

Os professores passaram a suscitar no aluno o desejo de aprender a ler, escrever e contar, explicitando a relação com os conhecimentos e o sentido do trabaIho escolar para desenvolver a capacidade de autoavaliação, negociando com eles diversos tipos de regras e contratos.

Além do mais, reforçaram o trabalho em equipe, elaborando projetos conjuntos, formando e renovando uma equipe pedagógica que confronta e analisa situações complexas, participando da gestão da escola, inclusive, no gerenciamento dos recursos e auxiliando na integração dos parceiros (bairros, associações de pais, professores, dentre outros), organizando e fazendo evoluir, dentro do âmbito escolar, a participação dos alunos.

Portanto, a formação continuada possibilitou refletir e buscar fundamentações teóricas para o desenvolvimento das práticas no contexto escolar, pois a partir deste acordo buscou-se qualificar o trabalho docente para auxiliar os alunos em seu processo de alfabetização. Por isso, acredita-se que as práticas desenvolvidas por essas professoras foram satisfatórias, considerando que os alunos envolveram-se e foram protagonistas no seu processo de ensino-aprendizagem.

Enfim, as ações desenvolvidas na formação do pacto foram colocadas em prática nas salas de aula do ciclo de alfabetização, dando ênfase à alfabetização, ao letramento, em língua portuguesa, matemática e à interdisciplinaridade, adquirindo-se as competências necessárias para a condução de processos de ensino e aprendizagem. Percebeu-se também que as professoras estão sempre atentas para as necessidades de colaboração, inovação e formação, sempre pensando na melhoria dos processos educativos da Rede Pública Municipal de Propriá/SE. 


\section{REFERÊNCIAS}

BRASIL. Decreto $n^{\circ}$ 6.094, de 24 de abril de 2007. Disponível em: <http://www.planalto.gov.br/ccivil_03/_ ato2007-2010/2007/decreto/d6094.htm $>$. Acesso em: 11 mar. 2019.

BRASIL. Secretaria de Educação Básica. Diretoria de Apoio à Gestão Educacional. Pacto Nacional pela Alfabetização na Idade Certa. Organização do Trabalho Pedagógico. Caderno 01. Brasília: MEC, SEB, 2014.

BRASIL. Secretaria de Educação Básica. Diretoria de Apoio à Gestão Educacional. Pacto Nacional pela Alfabetização na Idade Certa. A Organização do Trabalho Escolar e os Recursos Didáticos na Alfabetização. Caderno 04. Brasília: MEC, SEB, 2015.

FAZENDA, Ivani C. A. (org.) Didática e interdisciplinaridade. 13. ed. São Paulo: Papirus, 2008.

FREIRE, Paulo. Pedagogia da autonomia: saberes necessários à prática educativa. 21. ed. Sã In Pátio. Revista pedagógica (Porto Alegre, Brasil), n. 17, Maio-Jul., p. 8-12.
LIBÂNEO, J. C. Didática. 24. ed. São Paulo, Editora Cortez, 1994.

NÓVOA, Antônio. Escola nova. A revista do Professor. Ed. Abril, 2002.

\section{Formação de professores e profissão do-} cente. Lisboa: Dom Quixote, 1995.

PERRENOUD, Philippe. 10 novas competências para ensinar. Porto Alegre: Editora Artes Médicas Sul LTDA, 2000.

SILVA, Everson Melquiades Araújo. Dispositivos metodológicos para a formação continuada de professores: uma abordagem crítico-reflexiva. In: FERREIRA, Andrea Tereza Brito. São Paulo: Paz e Terra, 2002.

ZABALA, Antoni. A Prática Educativa. Editora ARTMED. Porto Alegre, 1998. 